\title{
Língua estrangeira e autonomia: um exemplo a partir do ensino de alemão no contexto brasileiro
}

\section{Foreign language and autonomy: an example from German teaching in Brazilian context}

\author{
Selma Martins Meireles*
}

\begin{abstract}
RESUMO
$\mathrm{O}$ artigo mostra, resumidamente, como as mudanças sociais decorrentes da globalização e das novas exigências do mercado de trabalho determinam mudanças no ensino, de modo a conferir aos aprendizes cada vez mais autonomia, criatividade e espírito crítico. Tomando como exemplo as principais abordagens metodológicas de ensino de alemão como língua estrangeira utilizadas no Brasil, mostra como as mesmas acompanham as mudanças na concepção do papel do aprendiz e da importância das línguas estrangeiras na sociedade. Ilustra também como os novos meios de comunicação de massa, como internet e TV a cabo, influenciam a aprendizagem dessas línguas e abrem novas possibilidades para os estudantes da escola pública.

Palavras-chave: ensino de língua estrangeira, ensino e autonomia, alemão como língua estrangeira.
\end{abstract}

\begin{abstract}
This paper portrays, in a summarized way, how social changes caused by globalization and new demands from the work market induce changes in the education such as to increase the students' capacity for autonomy, creativity and critical judgment. The several methodological approaches for teaching

* Doutora em Língua e Literatura Alemã pela USP. Professora da Faculdade de Filoso-
\end{abstract} fia, Letras e Ciências Humanas - USP/SP. selmamm@yahoo.com.br 
German as a foreign language employed in Brazil are used to demonstrate how they follow the changes in the concepts of student's role and social importance of foreign languages. It also illustrates how new mass media such as internet and cable TV affect the learning of foreign languages and open new possibilities for public school students.

Key-words: Foreign language teaching, education and autonomy, German as foreign language.

\section{As línguas estrangeiras no mundo atual}

Muitos brasileiros podem se perguntar o porquê da necessidade de aprender um idioma estrangeiro, já que podem exercer todas as suas atividades cotidianas em sua língua materna e seu contato com estrangeiros é bastante restrito (sendo que, na maioria das vezes, o estrangeiro também já domina o português de um modo satisfatório). Até há pouco tempo atrás, a necessidade e a possibilidade do aprendizado efetivo de uma língua estrangeira parecia remota para a maioria dos brasileiros: sendo um país continental e praticamente auto-suficiente nas atividades cotidianas, o contato com falantes de línguas estrangeiras parecia limitar-se às áreas de fronteira e a alguns poucos profissionais engajados no comércio exterior e no ramo de turismo. Para tanto, o domínio das estruturas e vocabulário empregados em determinadas situações de comunicação específicas parecia ser o bastante, sendo que o inglês aparecia praticamente como o único idioma estrangeiro necessário e, portanto, merecedor de um lugar no currículo das escolas da rede pública.

Hoje, ao início do século XXI, presenciamos, em um espaço de tempo muito curto, uma verdadeira revolução na ordem mundial no que se refere ao contato com culturas e produtos culturais em línguas estrangeiras. Os novos meios de comunicação de massa, como a internet e a TV a cabo, espalham-se cada vez mais e atingem pessoas de todas as camadas sociais, permitindo trocas constantes e rápidas e grande oferta de oportunidades de contato, segundo o interesse de cada indivíduo.

Pode-se argumentar que isso permanece ainda restrito às pessoas de maior poder aquisitivo em um país no qual muitos municípios ainda não contam sequer com energia elétrica e saneamento básico, mas o número de 
domicílios com computador e acesso à internet não pára de crescer e mesmo aqueles que não dispõem do aparelho em sua casa têm a oportunidade de utilizá-lo em cybercafés, escolas e repartições públicas, como os correios, por exemplo. De repente, a noção de um "mundo globalizado" deixou de ser exclusiva da esfera da economia e passou a invadir o dia-a-dia do cidadão comum, não apenas no seu trabalho, mas também no seu lazer e em atividades que lhe tragam satisfação pessoal. Com a união da internet e dos serviços dos correios, temos agora acesso a produtos de virtualmente todas as partes do mundo, sejam eles mercadorias concretas ou bens culturais como textos informativos, vídeos, músicas, "salas de bate-papo virtual" e muitos mais. O indivíduo passa a ter a sua capacidade de acessar informações e produtos e de apropriar-se deles menos dependente de intermediários como a escola ou especialistas e mais dirigida pelos seus interesses e características pessoais.

Desse modo, o cidadão comum deixou de ter a necessidade (ou mesmo a possibilidade) de um intermediário treinado especialmente para lhe dar acesso a contatos com conteúdos e pessoas falantes de línguas estrangeiras. Dominar um segundo ou mesmo um terceiro idioma passa a ser cada vez mais não apenas uma exigência do mercado de trabalho, mas parte integrante da vida atual. A nova situação impulsionou ainda mais a procura pelo inglês que, como lingua franca, é usado pela maior parte da comunidade da internet, porém, encontram-se cada vez mais páginas virtuais com diversas opções de idiomas e grande parte dos conteúdos disponibilizados por instituições e indivíduos de diferentes países são oferecidos em suas respectivas línguas maternas. Assim, também outras línguas estrangeiras passaram a ser mais atrativas, não só pelo interesse individual por conteúdos expressos em tais línguas, mas também pela curiosidade e/ou necessidade de entrar em contato com comunidades culturais que anteriormente não tinham grande espaço na mídia brasileira, como o espanhol, o japonês ou o alemão.

Está claro, portanto, que esta nova situação exige ou impulsiona fortemente o interesse dos indivíduos pelo domínio efetivo de uma ou mais línguas estrangeiras. Sublinho aqui o adjetivo efetivo, pois há uma grande distância entre "freqüentar aulas de língua estrangeira" e "dominar o idioma", e não me refiro aqui apenas à fluência ou à posse de um extenso vocabulário e conhecimento de regras gramaticais. Para ilustrar esse fato, gostaria de apresentar um exemplo baseado nas transformações dos métodos de ensino do alemão como língua estrangeira, ao qual me dedico já há mais de 15 anos. 


\section{Alemão como língua estrangeira no Brasil}

Apesar de geograficamente distante dos países de língua alemã (Alemanha, Áustria, Suíça, Lichtenstein e Luxemburgo), o Brasil tem muito contato com sua cultura. Está no Brasil a maior concentração de empresas alemãs fora da Alemanha e é patente o importante papel dos colonos falantes de alemão na região Sul do Brasil, bem como em comunidades menores em vários outros estados. O intercâmbio científico e tecnológico também é intenso e as relações diplomáticas, estáveis e baseadas em respeito mútuo. Contudo, a visibilidade da língua alemã no Brasil ainda é muito restrita (fora as regiões de colonização alemã no Sul do país) e o alemão é visto pela maioria dos brasileiros como uma língua "difícil" e apropriada apenas para assuntos altamente complexos - como mostra o texto da música de Caetano Veloso, que afirma "só ser possível filosofar em alemão".

Tal fato decorre do pouco contato pessoal entre brasileiros não descendentes de povos germânicos e a cultura de tais países. Fora os estereótipos de praxe, tão bem explorados pela propaganda - a figura do alemão loiro, gordo e vermelho, vestindo calças curtas de couro; que come salsichas e chucrute e bebe cerveja, ou do alemão frio e analítico, fanático pela eficiência e pontualidade -, um estudante do alemão como língua estrangeira tem, em geral, poucas possibilidades de entrar em contato com a realidade dos países de língua alemã, o que aumenta consideravelmente o grau de dificuldade em apropriar-se devidamente da língua estrangeira. Quero ressaltar que não me refiro aqui à situação dos aprendizes de alemão na região Sul do Brasil, onde o contato com a cultura germânica é muito grande, mas sim à situação do alemão como língua estrangeira no estado de São Paulo, que creio ser semelhante à dos aprendizes nas demais regiões do Brasil (embora mesmo os descendentes dos colonos germânicos na região Sul tivessem, até há pouco tempo, poucas chances de contato efetivo com a cultura atual dos países de língua alemã que não por correspondência pessoal com familiares europeus).

Por outro lado, exatamente essa fama de "difícil", "incompreensível", "misteriosa", "pertencente a um povo tão diferente" atrai muitos estudantes, que vêem no domínio do alemão um diferencial importante no mercado de trabalho e para o crescimento e a satisfação pessoal. O desenvolvimento dos métodos de ensino e aprendizagem do alemão como língua estrangeira no decorrer do século XX é um excelente espelho de como a concepção do 
papel do domínio de uma língua estrangeira tem se transformado de modo a adaptar-se cada vez mais às necessidades do mundo atual. Vejamos, de uma forma resumida, como isso ocorre, nos itens a seguir.

\section{Os métodos de ensino de alemão como língua estrangeira}

Os manuais didáticos e as aulas de alemão têm acompanhado as principais tendências mundiais do ensino de língua estrangeira, de modo que o é dito aqui é também válido para as demais línguas estrangeiras modernas. Como já mencionei, o alemão será usado como exemplo, já que corresponde à minha esfera de atuação. Também não vou me ater a detalhes muito específicos sobre os diversos métodos apresentados, pois quero aqui apenas salientar como eles refletem as relações entre o aprendiz, a língua estrangeira e o seu papel na sociedade.

a) O método de gramática e tradução

Este método, utilizado principalmente no início do século, surgiu da transferência da metodologia de ensino das línguas clássicas (latim, grego) para o ensino das línguas modernas. A língua alemã era apresentada aos aprendizes com base nas categorias da gramática latina e sintetizada em regras. Como os sistemas das duas línguas não são idênticos, criava-se um grande número de exceções, cujo domínio freqüentemente assumia, na aula, maior importância que as regras (cf. NEUNER, 1986, p. 10). A base para a descrição linguiística era a língua literária escrita, privilegiando o aspecto formal. A língua era concebida como uma construção formada por elementos organizados sistematicamente através de regras lógicas. Este conceito exclusivamente cognitivo do aprendizado da língua priorizava a capacidade de compreender e utilizar corretamente as regras de construção sintática. Como esse método se fixa na variante escrita, literária da língua, apresenta apenas enunciados corretos do ponto de vista formal, que devem ser imitados fielmente, fazendo do erro (no caso, a mal-formação gramatical) um mal a ser evitado a todo o custo. 
A utilização efetiva da língua com falantes nativos era completamente desprezada, pois, sendo um método utilizado primariamente no ensino de línguas mortas, não previa o uso da língua como meio de comunicação. A literatura era vista como testemunho da atividade intelectual de uma sociedade, cujos valores culturais positivos eram tidos como modelos a serem imitados pelos aprendizes - é claro que só se aprendiam as línguas de povos de maior prestígio econômico ou cultural, a fim de manter contatos com eles ou de atingir um "status superior de civilização". O aprendizado de uma língua estrangeira, privilégio de uma pequena elite cultural, tinha por objetivo auxiliar a formação intelectual do aluno. No Brasil, esse pensamento infelizmente ainda parece perdurar, pois os cursos universitários de Letras são muito freqüentemente considerados "cursos de luxo para intelectuais".

\section{b) Os métodos audiolinguais e audiovisuais}

A partir dos anos 20, com o surgimento de novas teorias psicológicas, os métodos de ensino de línguas procuraram aproximar-se do processo de aquisição da língua materna. Surgiu então o método direto, baseado na aquisição da linguagem por parte da criança e imitando o procedimento da mãe que ensina o bebê a falar. A língua passa a ser vista como comportamento verbal e o aprendizado como o resultado de um processo de condicionamento (baseado na teoria behaviourista de aprendizagem), através do treino contínuo de modelos morfológicos e sintáticos e estabelecimento de analogias. O objeto da análise lingüística é agora a língua falada, descrita sincrônica e estruturalmente como um sistema independente das demais línguas e com características próprias. A forma de expressão lingüística e a distribuição de suas unidades é examinada com relação à sua função (cf. NEUNER, 1986, p. 11).

Essa abordagem metodológica, que teve seu auge nas décadas de 50 e 60, surgiu como decorrência de novas concepções pedagógicas com relação ao aprendizado de línguas estrangeiras, considerando-o como elemento necessário à nova ordem mundial (após a aproximação e cooperação entre os vários países forçadas pela II Guerra Mundial e pelo advento da Guerra Fria), à maior integração entre os povos e trazendo a noção de 
“ensino de línguas estrangeiras para todos" (cf. NEunER, 1986, p. 12). Os avanços tecnológicos da sociedade da época (melhoria da aviação, dos automóveis e das estradas, com a reconstrução da Europa e a estabilidade econômica dos EUA) propiciavam uma maior mobilidade do cidadão comum, que entrava cada vez mais em contato com países de língua estrangeira e precisava comunicar-se em situações do cotidiano. A utilização crescente de meios auxiliares para o ensino de língua estrangeira (como slides, gravações, vídeos etc.) propiciou a evolução dos métodos audiolinguais para os audiovisuais.

Tanto os métodos audiolinguais como os audiovisuais privilegiam a língua falada e a situatividade em sala de aula, assim como a autenticidade dos padrões de expressão lingüística apresentados. Em oposição ao método de gramática e tradução, os novos métodos visavam possibilitar ao aprendiz uma comunicação eficiente em situações do dia-a-dia, através de um número pequeno de padrões de expressão lingüística e suas combinações, privilegiando-se os diálogos e descuidando das formas escritas de comunicação. No entanto, seu princípio de atuação, através da repetição exaustiva de padrões, acabava por reduzir a expressão criativa e gerava uma "linguagem de livro didático", na qual se reconhecem sentenças completas que por vezes soam inadequadas ao contexto social ou situacional em que são utilizadas.

No Brasil, apesar de os contatos com países estrangeiros, principalmente os EUA, terem se intensificado na época, permaneciam restritos a uma elite cultural e a um pequeno grupo de profissionais para os quais, certamente, os métodos audiolinguais e audiovisuais representaram um grande avanço, pois permitiam que interagissem melhor em situações do cotidiano do país estrangeiro. Porém, para a grande maioria dos aprendizes de alemão no Brasil, esse método ainda era de pouca valia, pois a probabilidade de uma viagem a um país de língua alemã era muito pequena e, assim, as situações apresentadas em aula eram apenas simulações que jamais seriam postas em prática. Desse modo, não havia interesse da escola pública no ensino da língua alemã fora das regiões de colonização germânica e o aprendizado da língua alemã continuou muito restrito. 


\section{c) O método comunicativo}

As abordagens comunicativas, surgidas na década de 70 e que atingiram seu auge nas décadas de 80/90, são voltadas para a comunicação e a pragmática e privilegiam o uso da língua estrangeira, concebendo-a como um meio de comunicação em situações cotidianas, principalmente no trabalho e no lazer (cf. NEUNER, 1986, p. 13). O sistema lingüístico é visto como um instrumento de interação humana, sendo que as formas e estruturas lingüísticas devem ser transmitidas em seu significado funcional. O centro do processo de aprendizagem não é mais a sentença ou o "padrão" correto, mas sim os processos de entendimento e os modos de expressão adequados a cada situação e contexto. Nesse método são considerados, além da gramática, o contexto sociolingüístico, os papéis dos falantes na situação, meios não lingüísticos e paralingüísticos (gestos, interjeições etc.), assim como a tipologia textual, objetivos, efeitos e estruturas típicas de situações de comunicação.

A cultura da língua estrangeira começa a adquirir maior importância, pois ela é o pano de fundo para todas as interações bem sucedidas, das quais o domínio da língua é parte primordial, mas não necessariamente decisiva. A cultura estrangeira é vista a partir da experiência do aprendiz na própria cultura, comparando-as e contrastando-as, permitindo uma ampliação e diferenciação das experiências culturais. O aprendizado passa a ser organizado em campos temáticos, o que propicia o estabelecimento de relações com a experiência prévia do aluno e aumenta a motivação, permitindo a utilização de materiais autênticos da cultura alemã, como folhetos, músicas etc. Textos escritos voltam a ser utilizados em aula, mas agora são textos informativos apresentados dentro de situações de comunicação autênticas. Textos ficcionais também são utilizados, porém, sempre como ponto de partida para reflexões e processos de compreensão global e seletiva similares aos que o aprendiz já conhece em sua língua materna.

A criação de simulações desloca o centro da aula da figura do professor para a do aluno, que é visto como agente do processo de aprendizagem, cabendo-lhe a seleção e o controle da forma de expressão lingüística através da qual realiza sua intenção comunicativa. Assim, toda a interação em sala de aula contribui para o treino e sedimentação do que foi aprendido, conferindo maior autonomia ao aprendiz. No Brasil, onde o sistema de ensino, mesmo nos dias atuais, ainda é bastante calcado na transmissão de conhecimentos 
pelo professor e sua "absorção" quase passiva pelos alunos, a dinâmica da aula comunicativa costuma causar uma certa insegurança inicial em alunos e professores: entre os primeiros, pela nova situação como sujeito ativo e responsável pela própria aprendizagem, nos últimos, pela impossibilidade de obter resultados homogêneos para todo o grupo e pela falta de controle imediato sobre a produção do aprendiz. Há também muitas vezes uma certa sensação de "perda de tempo" com os jogos lingüísticos e discussões em plenário, a qual é apenas ilusória, pois os procedimentos comunicativos propiciam maior autonomia e conscientização por parte do aluno, levando a uma aprendizagem mais efetiva no âmbito do uso da língua estrangeira como meio de comunicação.

Embora este método também se baseie fortemente em simulações de situações do cotidiano dos países de língua alemã, a utilização de materiais autênticos escritos e gravados em áudio ou em vídeo permite ao aprendiz um contato maior com a realidade da cultura estrangeira mesmo sem sair de seu país. Além disso, são criadas em aula situações de legítimo uso da língua estrangeira, como discussões e interações semidirigidas, que permitem ao aluno expressar suas opiniões e intenções próprias, desvinculadas dos modelos da cultura estrangeira. Toda a concepção da aula comunicativa já aponta para um aprendiz mais autônomo e responsável por sua própria aprendizagem, que seleciona e utiliza os meios e formas lingüísticas que julga mais adequados às suas intenções comunicativas. Isso o habilita, por exemplo, a interagir apropriadamente com falantes da língua estrangeira em seu próprio país (isto é, no Brasil), aumentando as chances de sucesso de alunos que pretendem utilizar o alemão sem sair do país, trabalhando em firmas alemãs ou escritórios de turismo locais. Em vista disso (ou por razões de demanda do mercado), o número de aprendizes de alemão cresceu nesse período, principalmente devido à integração de cursos de alemão em institutos particulares de ensino de línguas brasileiros. No início dos anos 90, o alemão passou a ser oferecido em alguns Centros de Ensino de Línguas de escolas públicas no Estado de São Paulo, devido principalmente ao esforço conjunto das associações de professores de língua estrangeira do estado e ao trabalho intensivo de divulgação dos órgãos alemães de fomento ao ensino do idioma. 


\section{d) A abordagem intercultural}

A abordagem intercultural tem muitos pontos em comum com o método comunicativo: ambos privilegiam o uso da língua estrangeira na comunicação, a aprendizagem cognitiva e criativa, a organização do conteúdo programático em grupos temáticos e da interação em sala de aula, com a mesma dinâmica de grupo. A principal diferença repousa no fato de que o método comunicativo ainda visa principalmente a capacitar o aluno a orientar-se e a integrar-se no cotidiano estrangeiro. A abordagem intercultural, por sua vez, visa propiciar ao aluno a oportunidade de "interpretar outras formas de comportamento, concepções e valores de uma cultura, tendo como pano de fundo sua própria cultura, suas experiências pessoais" (PIRES; ROHRMANN, 1990, p. 5). Enquanto a abordagem comunicativa informa o aluno sobre a realidade nos países de língua alemã, contrastando-a com a cultura do aprendiz (em outras palavras, dizendo: "na Alemanha/Áustria/Suíça... isto é assim, e na sua cultura, o que é diferente?"), a abordagem intercultural parte de fatos da língua e da cultura do aluno para interpretar seus correspondentes em outras línguas e culturas, entre elas a dos países de língua alemã (a questão então é: “como é isto no seu país? E na Alemanha? Como você vê essa questão nas duas culturas?"). Partindo da discussão e compreensão do universo do aluno, as duas culturas e as duas línguas são contrastadas, não mais se fixando na situação do aprendiz como estrangeiro na Alemanha, por exemplo, mas permitindo outras possibilidades, como o contato com a língua alemã no Brasil, no ambiente de trabalho ou com amigos alemães, ou ainda o contato indireto com os países de língua alemã, através de cartas e telefonemas - e, mais recentemente, do correio eletrônico. Assim, com a previsão da aprendizagem da língua alemã fora do contexto alemão, há uma maior ênfase na apreensão cognitiva da gramática, na compreensão oral e escrita e em modos de expressão específicos de cada cultura, como gestos e expressões idiomáticas. Os núcleos temáticos também são apresentados de forma diversa, apresentando inicialmente temas próximos à realidade do aluno (a sala de aula, interação com os colegas, experiências pessoais), expandindo-se em direção a temas mais universais (família, viagens etc.) e apenas mais tarde enfocando temas mais voltados à realidade dos países de língua alemã. 
Mas o mais importante na abordagem intercultural é, a meu ver, a valorização da cultura do aluno como igualmente legitimada em relação à cultura da língua estrangeira. Em todos os demais métodos, a língua e a cultura dos países germânicos é vista, de forma mais ou menos patente, como um paradigma a ser seguido: no método de gramática e tradução, como um modelo intelectual; nos métodos audiolinguais e audiovisuais, como padrões a serem imitados para conseguir a aceitação em situações no estrangeiro; no método comunicativo, como modelos de situações que o falante estrangeiro irá enfrentar caso queira trabalhar ou estudar nos países de língua alemã. Apenas no método intercultural o aprendiz não é convidado a despir-se de suas características culturais e assumir ou assimilar novas regras de conduta e pensamento. $\mathrm{Na}$ abordagem intercultural, o aprendiz vê sua cultura e sua língua como uma dentre várias possibilidades igualmente desejáveis e válidas. Apenas, por razões de sua escolha pessoal, decidiu-se a conhecer mais a fundo as peculiaridades da língua alemã e da cultura dos países que a utilizam, estando livre para escolher, conscientemente, o quanto dessa cultura ele irá incorporar. O método comunicativo, no meu entender, evita situações que normalmente são descritas como "relações entre colonizado e colonizador": a transmissão de uma língua e cultura não servem para criar relações de inferioridade ou superioridade entre os povos, pois não há um modelo a ser seguido, ou uma cultura "melhor" do que a outra. Tornamo-nos conscientes das diferentes possibilidades que os seres humanos elegem para regular suas vidas, aprendemos a conviver com elas e, mais importante ainda, a respeitálas em suas singularidades, o que inclui manter a consciência e o orgulho de minhas particularidades frente às dos demais.

\section{Língua estrangeira e encontro de culturas}

Com os atuais regimes econômicos e trabalhistas, a responsabilidade pela formação do ser humano e do futuro cidadão tem passado cada vez mais para a escola, em vista da desagregação da antiga família numerosa em pequenas células familiares, onde os dois cônjuges trabalham fora e pouco tempo têm para se dedicarem às crianças. Estas, por sua vez, cada vez mais exigidas pelas expectativas de seus pais com vistas a uma futura boa colocação profissional, passam cada vez mais tempo na escola ou em 
cursos de diversas habilidades (natação, balé, inglês, computação etc.). Vemos claramente, então, que a escola é cada vez mais exigida a fornecer ao indivíduo ferramentas que lhe permitam situar-se e movimentar-se no mundo atual. Entre essas ferramentas está o domínio de uma ou mais línguas estrangeiras.

A concretização do Mercosul levou à primeira tentativa de introdução do espanhol como uma segunda língua estrangeira no currículo escolar da rede pública de ensino. Na esteira do oferecimento de novas possibilidades para estudantes que não desejassem se restringir ao inglês, houve um grande movimento por parte dos professores de línguas estrangeiras no sentido de sensibilizar as autoridades do ensino a oferecerem também, segundo os interesses das diversas comunidades escolares, a possibilidade de aprendizado de outras línguas estrangeiras além do inglês e do espanhol. Assim, foram criados os Centros de Ensino de Línguas Estrangeiras, que receberam várias denominações regionais, agregados às escolas públicas e mantidos com recursos do Estado. Desse modo, de acordo com o interesse de cada região, cursos de diversas línguas estrangeiras (como espanhol, francês, italiano, alemão, japonês e mesmo de algumas línguas menos conhecidas, como o lituano ou o polonês no Sul do Brasil) podiam ser oferecidos à comunidade escolar de menor poder aquisitivo. Desde a sua criação, os Centros de Ensino de Línguas têm passado por diversas dificuldades e, em São Paulo, grande parte deles foi desativada, configurando um triste retrocesso. Mas talvez seja aqui o momento de reiterar a importância de uma política de plurilingüismo no Brasil, em vista da situação mundial atual, dos novos meios de comunicação e das exigências do moderno mercado de trabalho.

Em primeiro lugar, já mostrei como o advento da internet e da TV a cabo começa a colocar o cidadão comum cada vez mais em contato com situações nas quais ele precisa se confrontar com um idioma e - mais importante ainda - com uma cultura e uma visão de mundo diferentes da sua. A mídia oferece a todos um sem-número de retratos e mensagens multiculturais que tanto se complementam e se reforçam como se chocam e se combatem continuamente. Somos bombardeados com imagens simultâneas da burka árabe, da tanga da "garota de Ipanema", do programa militar de satélites "Guerra nas Estrelas", das orações do Dalai-Lama e do Papa, da fome na África, da epidemia de dengue no Brasil, das regras rígidas das sociedades japonesa e coreana (contra as quais a já lendária "malemolência" do torcedor brasileiro certamente se chocou na última Copa 
do Mundo) e muitas outras mais. Como nos orientarmos em meio a tantos flashes de informação fragmentados e justapostos, aparentemente sem qualquer critério?

Os "novos tempos" exigem do cidadão que ele seja capaz de movimentar-se em meio a estímulos dos mais variados. Os profissionais mais procurados pelo mercado de trabalho moderno são aqueles capazes de integrar vários ramos do conhecimento - e não apenas do conhecimento tecnológico, mas também do trato com outras pessoas e, cada vez mais, com pessoas de diferentes backgrounds socioculturais. A tão decantada "inteligência emocional" dos manuais de auto-ajuda e sucesso nos negócios nada mais é do que o reconhecimento (e apropriação, com uma nova roupagem) daquilo que os cientistas e profissionais das ciências humanas têm preconizado há muito tempo: a sociedade é feita pelos seres humanos, não pelas máquinas e processos tecnológicos, e apenas com o aperfeiçoamento e a valorização do material humano a sociedade moderna pode se estabilizar e seguir o seu caminho.

As exigências do mercado de trabalho e da sociedade atual não têm passado despercebidas pela escola, como mostram as novas diretrizes para o ensino médio brasileiro e sua relação com o ensino profissionalizante. Nesse contexto, um artigo de Acacia Kuenzer, divulgado na homepage da Faculdade de Educação da UFPR, descreve como as recentes mudanças na sociedade influenciaram as relações entre indivíduo, aprendizagem e seu papel social:

As mudanças ocorridas no mundo do trabalho apontam para uma nova forma de relação entre ciência e trabalho, onde as formas de fazer, determinadas a partir de processos técnicos simplificados, restritos geralmente a uma área do conhecimento, transparentes e portanto facilmente identificáveis e estáveis, passam a ser substituídas por ações que articulem conhecimento científico, capacidades cognitivas superiores e capacidade de intervenção crítica e criativa em frente a situações não previstas, que exigem soluções rápidas, originais e teoricamente fundamentadas, para responder ao caráter de dinamicidade, complexidade, interdisciplinaridade e opacidade que caracteriza a tecnologia na contemporaneidade.

Esta nova realidade exige novas formas de mediação entre o homem e o conhecimento, que já não se esgotam no trabalho ou no desenvolvimento da memorização de conteúdos ou formas de fazer (...). a formação humana 
para a vida social e produtiva (...) passa a ser concebida como resultante da articulação de diferentes elementos, através da mediação das relações que ocorrem no trabalho e na vida coletivos, resultando de vários determinantes subjetivos e objetivos, como a primeira socialização, a natureza das relações sociais vividas e suas articulações, a escolaridade, o acesso a informações, o domínio do método científico, a origem de classe, a duração e profundidade das experiências laborais e sociais, o acesso a espaços, saberes, manifestações científicas e culturais, e assim por diante. Em decorrência, a qualificação profissional passa a repousar sobre conhecimentos e habilidades cognitivas e comportamentais que permitam ao cidadão/produtor chegar ao domínio intelectual da técnica e das formas de organização social de modo a ser capaz de criar soluções originais para problemas novos que exigem criatividade, a partir do domínio do conhecimento.

Para tanto, é preciso outro tipo de pedagogia (...) O objetivo a ser atingido é a capacidade para lidar com a incerteza, substituindo a rigidez pela flexibilidade e rapidez, de modo a atender a demandas dinâmicas, que se diversificam em qualidade e quantidade, não para ajustar-se, mas para participar como sujeito na construção de uma sociedade onde o resultado da produção material e cultural esteja disponível para todos, de modo a assegurar qualidade de vida e preservar a natureza (KUENZER, 2002).

Nesse contexto, o aprendiz de língua estrangeira tem duas grandes vantagens em relação àqueles que não passaram por tal experiência: primeiro, ele já foi sensibilizado e "treinado" como um sujeito ativo, autônomo e crítico pelas novas abordagens metodológicas. Além disso, a possibilidade de contato com outras culturas e vivências socioculturais aumenta sua criatividade e tolerância a experiências diversas e/ou inesperadas.

\section{A abordagem intercultural e o mundo globalizado}

Através do exemplo do ensino de alemão no Brasil, pudemos ver como as diversas abordagens de ensino de língua estrangeira acompanharam a trajetória da difusão da escolaridade e da instrução para todas as camadas sociais, no Brasil e no mundo, e a crescente valorização da autonomia do aprendiz. Inicialmente destinado a uma pequena elite econômica e intelectual, o ensino de línguas estrangeiras foi sendo paulatinamente integrado ao currículo das escolas em geral, aproximando-se das necessidades reais dos 
cidadãos. Ao mesmo tempo, os aprendizes são cada vez mais estimulados a se tornarem sujeitos ativos e controladores de sua própria aprendizagem, porque essa é a postura que a sociedade moderna exige do indivíduo, que ele seja crítico e pensante, capaz de selecionar o que deseja ou necessita no mar de informações que lhe são impostas diariamente por todos os canais da mídia e que seja capaz de reagir criativamente às diferentes situações e problemas que se lhe apresentam no cotidiano. Nas palavras de PIAGET (1998), "pensar é procurar por si próprio, é criticar livremente e é demonstrar de forma autônoma". O pensamento supõe então o jogo livre das funções intelectuais e não o trabalho sob pressão e a repetição verbal.

Um aprendiz autônomo e consciente de uma língua estrangeira é capaz de utilizar adequadamente todos os canais à sua disposição para alargar seus horizontes, aumentar seu conhecimento lingüístico e cultural do alemão ou de qualquer outro grupo cultural e formar opiniões que, por sua vez, irão enriquecer o pool de experiências ao qual recorre para suas decisões diárias. Principalmente, ele será menos suscetível a estereótipos e a manipulações e terá um comportamento mais crítico e tolerante frente ao estrangeiro, àquilo que lhe é "estranho" ou desconhecido, sabendo que não é necessariamente algo a ser combatido, temido ou copiado indiscriminadamente.

Por outro lado, no âmbito do crescimento pessoal e profissional, o oferecimento da oportunidade de aprendizado de várias línguas estrangeiras a alunos da rede pública, mesmo ameaçado no estado de São Paulo, já deu seus frutos visíveis. Em comparação com outros cursos de cunho profissionalizante ou com caráter de especialização, os cursos de línguas estrangeiras são pouco custosos: necessita-se apenas de lousa, giz, livro didático, gravador e fitas e de um professor bem treinado para oferecer aos alunos da rede pública uma oportunidade de diferenciar-se no mercado de trabalho. Alguns ex-alunos de Centros de Ensino de Línguas Estrangeiras já aparecem como estudantes dos cursos de Letras da Universidade de São Paulo, com vistas a se tornarem professores, tradutores ou mesmo pesquisadores em suas respectivas línguas estrangeiras, o que pode significar um grande avanço em suas perspectivas pessoais. Em razão das exigências da vida atual, do mercado de trabalho e da necessidade de oferecer oportunidades iguais de desenvolvimento a todas as camadas econômicas da sociedade brasileira, a escola pública não pode mais se furtar ao plurilingüismo e às abordagens de ensino que desenvolvem nos aprendizes autonomia, espírito crítico e consciência das particularidades de sua cultura e de seu lugar num mundo globalizado. 


\section{REFERÊNCIAS}

KUENZER, A. Z. O Ensino Médio agora é para a vida: entre o pretendido, o dito e o feito. Disponível em: <http://educacao.ufpr.br> Acesso em: 21 maio 2002.

NEUNER, G. et. al. Übungstypologie zum kommunikativen Unterricht. Berlin/Munique: Langenscheidt, 1986.

PIAGET, J. Sobre a pedagogia. São Paulo: Casa do Psicólogo, 1998.

PIRES, M. C. A.; ROHRMANN, L. Sprachbrücke: Deutsch als Fremdsprache-Manual do Professor. São Paulo: EPU, 1990.

Texto recebido em 22 jul. 2002 Texto aprovado em 26 ago. 2002 